\title{
Analyses of Dynamic Stakeholder Views for CNPC
}

\author{
Huijun Li \\ School of Economic and Management \\ China Petroleum Pipline University \\ Hebei 065000, China \\ E-mail: lihuijun1106@126.com \\ Dengkui Wang \\ CPP International, China Petroleum Pipeline Bureau \\ Hebei 065000, China \\ E-mail:wdengkui@gmail.com
}

\begin{abstract}
This paper tries to analyze the stakeholder view development of CNPC and explain the way in which CNPC grew up by analyzing the historical situation of company and Chinese special changing political and economic environment in which CNPC was run. After analyzing, this report will explain why some stakeholders counted while others did not during periods. Then CNPC's stakeholders in different periods will be analyzed under certain circumstances in Chinese oil and gas industry backgrounds. What were the guidelines for CNPC to prioritize various stakeholders? Did the framework about stakeholders work in CNPC considering the fact that CNPC was run in much more different political regime from western countries, especially North America and European countries. Subsequently, the paper will analyze challenges about the how to resolve the stakeholder issues which CNPC has to face when it implements its globalization strategy.
\end{abstract}

\section{Keywords: CNPC, Stakeholder View, Oil Industry Globalization}

CNPC was the focus of mass media of all over the world in 1998 because CNPC lay off more than three hundred thousand employees dramatically. The downsizing was the fuse of the riot in Daqing in 2002, the most important oil and gas city in China and this riot spread quickly throughout oil and gas industry. That event really made CNPC in big trouble. After five years, CNPC was the focus again in 2003 because of the gas well blowout in Kai county Chongqing City. That disaster in which more than 243 rural people who lived close to the gas well died and several thousand of people were injured made CNPC more famous than any other corporation in China and even in the world. Again the gas well blowout pulled CNPC into trouble. However after two years, in November 13, Jilin Petrochemical Plant explosion (Jilin Petrochemical Plant, the largest chemical Plant of PetroChina, a subsidiary of CNPC) contaminated the Songhuajiang River which is one of the largest river in the North-East China and also the main drinking-water resource of residents of Harbin city, the capital of Heilongjiang province and of Khabarovsk city of the Russian. This water contamination caused Harbin to suspend tap water for more than 4 days and made residents panic. This event affected 9 million people in two countries. Many people who really concern about CNPC were wondering what were going on with CNPC.

In order to analyze CNPC's stakeholder view development, firstly, I would like to review the literature about shareholder theories so that they can be applied to interpret the behavior of CNPC.

\section{Literature review}

The view of stakeholder is developing for a long time. The debate of the conception is very hot between scholars and strategist and most of them are not convincible. Generally, there are two points of review. One is the broad definition and the other is the narrow one. The broad definition held by Freeman (1984:46) is that a stakeholder in an organization is any group or individual who can affect or is affected by the achievement of the organization's objectives. The narrow definition held by Clarkson (1994.5) is that voluntary stakeholders bear some form of risk as a result of having invested some form of capital, human or financial, something of value, in a firm. Involuntary stakeholders are placed at risk as a result of a firm's activities. But without the element of risk there is no stake. Comparing both definitions, we can find major difference between them, narrow views---based on the practical reality of limited resources---attempt to define 
relevant groups in terms of their direct relevance to the firm's core economic interests---some scholars narrow the field of relevant groups in terms of moral claims. While broad views---based on the empirical reality that company can affect or be affected by everyone---is difficult to apply by managers (Ronald K Mitchell: 1997). Both of them can not precisely explain the meaning of stakeholder. The broad one would include all groups because everything is relevant to and affect each other.

Therefore Ronald K Mitchell (1997) developed a new theory to identify different categories of stakeholders. According to his theory, three contributes of stakeholders should be considered in sorting stakeholders. These three contributes are power, legitimacy and urgency. Stakeholders who possess different attributes will be sorted into dormant, dominant, discretionary, definitive, dangerous and dependent and demanding. (See the figure 1) then he sort all these stakeholders into three classes: latent stakeholders who possess only one attribute, expectant stakeholders who possess two attributes and definitive stakeholders who possess three attributes completely.

\section{Figure 1}

Simultaneously, there is still another view to the stakeholders. James E. Post, Lee E. Preston, and Sybille Sachs (2002) hold that managers should manage the extended enterprise. From their point of review, the extended enterprise concept is enlarged to include not only the focal firm interactions with other businesses but also its relationship with stakeholders, both internal and external. They classify stakeholders into three categories, resource-based, industry structure-based and social political-based stakeholders. In this theory, manager should integrate all stakeholders and view companies as extended enterprise to make strategies and implement them so that the companies can minimize the risk that they would face in the future development.

At the same time, Jeremy Hall and Harrie Vredenburg point out that all companies should realize the stakeholder ambiguity and manage stakeholder ambiguity to minimize the managerial risk. Especially to the multi-national companies, they should cautiously direct the stakeholder ambiguity developing and decide which direction they will develop.

However, do all these stakeholder theory successfully explain the way in which CNPC is operated? Should we apply them with some modification to match the special situation in china? What should CNPC adjust its views of shareholders to face the challenges coming from other unpredictable stakeholders so that CNPC enables itself to be sustainable?

Firstly, I would like to take a quick look at the background of CNPC.

\section{Backgrounds of CNPC}

China National Petroleum Corporation is the largest oil and gas producer in China. CNPC was founded in 1988 based on the petroleum industry ministry founded in 1949 as soon as People's Republic of China was founded. At that time the main mission of CNPC was to produce crude oil and gas to meet the energy demand of Chinese domestic industry according to the central government's economic plan. One of its subsidiaries, PetroChina was listed both in Hong Kong and New York Stock Exchange in April 2004. During the more than two decades development, CNPC is one of the world-wide leading oil and gas integrated companies with a revenue of 570.68 billion Yuan and profit of 72.48 billion Yuan in 2004. Now CNPC ranked in the top ten in the world fifty largest integrated oil and gas companies. Through more than two decades development, CNPC expanded internationally. Now, it has been present in Africa, Mid-East, Middle-Asia, Europe, North America and South America.

China is one of largest developing country in the world. In these years, China's economy is developing very stably and quickly. The GDP growth rate is keeping above $8 \%$, last years it even exceeded $9 \%$ and this year it is expected to be $9.2 \%$. The tremendous growth rate attributes to the economic and political reforms. Strong GDP growth rate is forcing the energy demand increasing quickly. Now China is the second largest oil and gas consumer only after United States. However, the domestic oil and gas production is far lower than the energy demand. The bullish demand is luring oil and gas companies to expand internationally to acquire the reserve and strategic assets all over the world. Therefore CNPC, Sinopec and CNOOC (China National Offshore Oil Corporation), three largest state holding oil and gas companies are experiencing to acquire assets in the world. In 2005 October, CNPC successfully acquired Calgary-based PK Company and purchased the Ecuador assets from EnCana, the largest energy company in Canada. CNOOC failed to acquire California-based Unocal in 2004.

\section{The Stakeholder view of CNPC in 1988-1998}

Because of the special political environment and economy, CNPC in 1988, actually was not only a company but also official organization. CNPC was founded at the base of the Petroleum Ministry. It took over most of the social responsibilities that Petroleum Ministry used to take during 1949 to 1988. A conclusion can be made that CNPC was not an independent company at all. At that time, the entire senior managers were appointed by the government. Actually CNPC's did not behavior in the way a normal company did. CNPC fully financially sponsored and managed many 
universities, colleges and technical schools which should be financially sponsored by government according to Chinese laws and policies. At the same time, CNPC also paid medical insurance and pension plan for all employees after they retired.

From the economic perspective, the main task of CNPC at that time was to meet the demand of national energy demand under the command economy system. Each year, the central government made an oil and gas consumption budget plan which would guide the operation of CNPC. CNPC just acted as an implementer with very little freedom. All it would do was just to follow the plan. Therefore CNPC could pursue production increasing without considering expenses. This was somewhat ridiculous in eyes of westerners.

In fact, in that period, CNPC had a very heavy burden of social responsibilities. The main task of CNPC at that time was to meet the energy budget of central government based on the self-reliance policy of central government. If we analyze the behavior of CNPC of that period of time, we can conclude that CNPC only concerned one stakeholder, that is, government. Chinese central government had three attributes according to stakeholder theory of Ronald K Mitchell (1997). Government had sovereign power to influence and control the company. All senior officers were appointed by the central government and all of them were viewed as officials by the ordinary people other than businessmen. Certainly, the central government could dismiss anyone in the senior management who did not run business in the way government desired. The president of CNPC was treated equally to the minister. In most of employees' minds, the president still was the minister of oil ministry that actually had not existed since 1988 .

The other attribute of stakeholder was also possessed by the government. Legitimacy was the most powerful attribute of government. At that time, government claimed that it dedicate to creating a communism society in which everyone was treated equally and paid by the need eventually although the first phase was paid according to contribution of citizens to the development of society. In the early 1980's almost no one doubted this great dream. What the government did was broadly accepted by ordinary people with out any suspicion. Since CNPC inherited the responsibilities, in the ordinary citizens, they were used to view CNPC as a governmental organization other than a real company whose aim was to maximize shareholders' value. Above all, CNPC itself also assumed it was a governmental organization.

The government also obviously has the attribute of urgency. From CNPC perspective, the government was the policy maker and supervisor. In the CNPC's priority, the government was in the first place to satisfy. All operations were centered on the central government's economic plan made in the very beginning of each year. Therefore, all the decision about production and price of product made by CNPC absolutely based on the central government's annual economic plan.

Therefore we can conclude that the government was the definitive stakeholder according to the stakeholder theory of Ronald K Mitchell (1997). Then we can understand why CNPC run businesses in this way which was not understandable from the view of westerners. For CNPC, the most important stakeholder was the government. Were there some other stakeholders? How about other stakeholders at that time?

Now let us take a look at other stakeholders. Firstly, we take a look at the first category of stakeholders, employees, investors, lenders and shareholders customers and users. At that time, employees of CNPC were registered employees who were pride of being members of CNPC. All workers were regarded as owners of the state-owned enterprises as well as the owners of the country. If CNPC satisfied the government which represented all people in this country, it also satisfied the workers employees of CNPC. Actually, during 1988-1998, there were very a few investors other than the government or banks owned by government. Like most of the industry which were critical to the economy development such as electricity, and coal industry, were directly invested and sponsored by the government. All these industries could be very easily financed by the state-owned investing banks once they had a need to develop new projects.

During this period, Chinese government conducted self-reliance oil and gas policy so that all oil and gas production had only one aim of meeting the domestic demand from other industries. Therefore most of the stakeholders were state-owned organizations which also directly or indirectly controlled by different levels governments. We can conclude that the most important customer was government.

Judging from analysis above, we can come up a conclusion that all the resource-based stakeholders eventually converged on the government. This is why CNPC run business this way.

This is the case for the rest of categories of stakeholders, such as structure-based and political and social-based stakeholders.

In fact, the stakeholder view affected the operation of CNPC dramatically. During that period, the entire decision making was based on appealing to the government. CNPC did not consider economic equally to the social responsibilities. Actually CNPC had to suffer the heavy burden of social responsibilities the expense of the economic value. This was why CNPC was perceived as not being competitive by the western company although in term of the reserves and the number of employees, CNPC should be listed in the world-wide largest companies and should be known and recognized by at least energy industry in the world. Actually, it was not. In eyes of western, CNPC was 
agency of government other than a real company which should had an aim to maximize the shareholders' value. They noticed that CNPC put so much money into the public infrastructure, such as road construction, city utilities and in education and in the pension plan.

Therefore, CNPC had an excellent reputation and no one suspected it was socially responsible during that period. All other industry was called on to learn from petroleum industry because of the highly praised socially responsible image. Even now, the "Iron Man", Wang Jinxi who was a hero because he successfully avoided a disaster by stopping an oil well blowout by jumping into the well is still highly praised by contemporary and still encouraging all citizens to work hard for economic development. He saved many people lives and created economic value for the Daqing oil Field and positive externalities for CNPC.

\section{The Stakeholder View of CNPC in 1998-2003}

However, with time going on and economic and political reforming, the business environment was changing gradually. Simultaneously, with opening policy, influx of foreign companies made Chinese companies reconsider their situation and had to figure out strategies of how to compete with giants from outside China. CNPC was not exceptional. It faced the challenges from huge competitors, such as BP, Royal Dutch Shell, and Exxonmobil. In 1998, Chinese government was negotiating with the members of WTO and it seemed China would be a member of WTO any time after great progress in the negotiation. Many multi-national companies were ready to enter the huge potential market to extend the operation in China. CNPC had to face the powerful competition from giants on the same stage. Actually, these companies demonstrated strong presence throughout China with advanced technology and managerial skills. CNPC was dwarfed by them. CNPC realized that the gaps were unimaginably broad both in term of economic value and management. CNPC began to worry about situations. How would CNPC compete with giants from outside China and what would CNPC compete with them on?

After painful consideration, CNPC found out it was time to change right now in 1998. CNPC had no choice but reform the outdate management style and fundamental philosophy of doing businesses. CNPC realized that it was not a government agency any more since it was founded in 1988 and it had no obligation to undertake tremendous social burden which should be considered by government which collected tax from all companies and citizens. Since CNPC was taxed by the government under laws, CNPC should not have been imposed dual obligation to be socially responsible. Simultaneously Chinese government also realized that Chinese major state holding companies were losing the competitiveness. Both knew something should happen to better the position CNPC now facing.

Therefore, CNPC supported by the central government began to implement policies which aimed to improve the efficiency and economic value of the company. First thing that CNPC and central government figured out was that the size of the company was unimaginably huge in terms of its employment and social burdens in eyes of the counterparts outside China although in terms of annual production and reserves, CNPC was one of the largest petroleum companies in the world. While in term of the productivity, CNPC was on the bottom of the largest oil and gas companies in the world. That position was really embarrassed and made CNPC less attractive to raise capital in the world capital market.

A campaign that was designed to enhance the competitiveness of major state owned companies including CNPC and Sinopec, two largest oil and gas companies in energy sector, was launched in 1998. In 1998, CNPC was transformed from upstream oil and gas producer into a vertically integrated petroleum company operating in the upstream and middle stream as well as downstream. In order to inject viability to CNPC so that CNPC was more competitive, Chinese government permitted CNPC to implement downsizing plan which was unlikely to happen in the past fifty years since 1949. That event symbolized that CNPC began to reconsider its stakeholders rather than only considering the government's stake.

This downsizing reduced more than three hundred thousand employees, nearly one fourth of the total number of employees. Simultaneously it has embarked on a new company, PetroChina, was created. This company controls CNPC's exploration and production activities in China, the production and sale of oil products and petrochemicals and the supply and transmission of gas within China while overseas investments, the service companies and much of the social burden were retained by the parent company CNPC. CNPC took it for granted that PetroChina would be easier to raise capital, given integration enabled it grow quickly and would be renowned in the world compared to the parent company CNPC. However it was not the case. In 2000, the IPO (Initial Public Offering) of PetroChina was launched in the Hong Kong and New York Stock Exchange. Opposite to the expectation, the response to the IPO of PetroCHina was surprisingly lukewarm. CNPC had to reconsider itself. What was wrong with CNPC?

Disasters usually do not happen solely. After the unexpected IPO result, in 2002, the riot broke out because of the consequence of the downsizing conducted three years ago. Laid-off employees in Daqing oil field as well as other oil fields claimed that CNPC laid off them by cheating and taking advantages of the unbalance information sources. In that downsizing, CNPC only offered compensation of maximum amount of one hundred thousand Yuan to employees who were willing to quit from the CNPC. Because of the economic and political situation, many employees, who 
usually were older and not skillful and uneducated while were the first generation of the oil and gas industry, were scared by the unpromising future and did not want to lose this chance to exercise the option of getting some immediate money back. Otherwise, they would really be in trouble to raise the family and support children to complete education. However, their dream did not come true. They were stressful because of increasing medical insurance and pension plan. According to the downsizing policy of CNPC, once employees quitted from the company, they had to pay medical insurance and pension plan themselves. In 2002, CNPC was accused of cheating them to lure them to quit from the company without adequate compensation. That riot made CNPC in trouble deeply.

Why did that happen? Now, we can analyze it by analyzing the stakeholder view of CNPC.

Why did CNPC conduct reforms to restructure the company and downsize the company? Initially, it was directed by the policies of central government. Before China became a member of WTO, Chinese government had a strong desire to arm Chinese companies and make them more competitive so that they could more likely survive in the sever competition from multinational companies. The up-down policy enabled CNPC easier to implement the downsizing and restructuring. However, CNPC made mistakes that time. CNPC overlooked the stake of these laid-off employees in the downsizing. CNPC emphasize too much on the economic value of the company. The most important factors for CNPC were to enhance the competitive advantage over the competitors all over the world. The CNPC thought that government would take over the consequence of downsizing, such as pension and medical insurance. However, the government was not ready to do that. Therefore conflicts came up. The employees used to be regarded as the owners of this nation while now they were on the edge of surviving. The huge difference made them really uncomfortable. On the CNPC side, they assumed that they were laid-off willingly with compensation and it was fair to them. CNPC failed to realize that the society was not ready to accept them and accommodate them. It was not the right time for CNPC to get rid of the social burden away immediately. The complexity was not realized by the company. The employees and society were interdependent. CNPC had to consider them together instead of separately.

Simultaneously, "the lukewarm response to PetroChina's IPO reflected a wide range of concerns from the stakeholders out side China. Foremost among these was a lack of confidence in the ability of the management to cut costs and deliver shareholder value in what was a large and outdated corporation; and the absence of clarity about how the funds raised would be used. These realistic commercial concerns were supplemented by political ones. Shareholders could not believe that CNPC would run business with best interest of shareholders given that government still was the biggest stakeholder. CNPC holds 90\% shares of PetroChina. They naturally linked CNPC with government and suspected that CNPC would perhaps have an intention to appeal to the Chinese government at the expense of the other shareholders' value.

In advance of the issue, human rights groups succeeded in stirring up vocal protest at CNPC's investments in Sudan and its potential investments in Tibet. This event indicated that stakeholder ambiguity began to affect CNPC. Human rights were never an issue in its history.

All these events forced CNPC to redefine its stakeholders. The stakeholder was more than government. And the mission of the company was not only to pursue economic value or undertake too many social burdens. CNPC had to extend its stakeholder views. Otherwise, CNPC could not be sustainable not only in domestic market but also in the oversea market.

During this period, CNPC added giants from outside china as important stakeholders as well as government in term of power, urgency and legitimacy. They are powerful to influence CNPC. Once they are ready to compete with CNPC in Chinese market or make a decision to formulate strategy alliances with CNPC, CNPC would be challenged or beneficial from them. Judging from CNPC's side, these international oil and gas companies are powerful and urgent. According to the stakeholder theory, they are dangerous stakeholder. CNPC had to consider it actively. At the same time, laid-off employees were also stake to CNPC. However, CNPC overlooked stakes of them. Actually, they possessed two attributes of the stakeholder: power and legitimacy. Because laid-off employees could not be accepted by the society, they were hard to maintain their normal life. They had to turn to the CNPC which they had contributed a lot with almost whole life from the very beginning of development of the oil industry. Actually, most of the people in China sympathized with these laid-off employees and could not understand these facts. The combination of sympathies from other people and laid-off employees' strong desire to maintain a normal life imposed significant influential power and legitimacy to CNPC.CNPC failed to realize that so that the riot spread quickly and eventually was solved with help of central government with offering solution package to them.

\section{The Stakeholder view in 2003-2005}

After unexpected result of IPO both in the Hong Kong market and New York market, CNPC desired to enhance investors' confidence. Therefore, they tried various ways to cut the cost. During this period, CNPC emphasize more on the economic value of the company. This policy really worked. In 2003, CNPC achieved record profit and more confident information was transferred to investors. It seemed that CNPC was on the right track. But December 23, 2003, 
gas well blowout accident had a huge impact on stakeholders. They realized that CNPC was far from on the right track. It might be on the other extreme, emphasizing too much on the economic value and overlooking the society in which it was operating. This tragedy killed 243 people and injured several thousand of people who live around the well. That accident was enough to ruin the good social reputation accumulated in the past years. Many social scientists exclaimed that CNPC was not a socially responsible enterprise any more although it used to be high praised for its social responsibilities.

In order to enhance the competitive advantage, CNPC launched a campaign to reduce the cost. Therefore, many costs which should occur were avoided. The hidden troubles were generated. After the gas well blowout, many experts pointed out that operating teams of that gas well never explained dangers and the way to escape from the well blowing to residents around the gas well because they were tied up by the tight work schedule. Because of the high risk, there should not be any residents one kilometer in circumference around the well. CNPC should relocate them after the well was put into operation. At least, CNPC should have informed them of the dangers and how to deal with accidents which would happen. However, CNPC failed to do what it should have been done.

If we take a deep look at the disaster, we can find out deep reason is that CNPC began to overlook social responsibilities and pursue economic value unilaterally. Therefore, CNPC just appealed to shareholders and did everything possible to maximize shareholders value. That symbolized that CNPC emphasized on all shareholders other than government only.

Government still was the most important stakeholder in term of the power, urgency and legitimacy. However, CNPC, as a public company, it had to maximize the all shareholders' value to obtain good reputation and change the original image of inefficiency in operation. This time, CNPC destroyed itself by overlooking social responsibilities and over concentrating on the economic value. British Petroleum Corporation sold out all shares it held as soon as it was informed of the accident. Share price began to slip quickly in one day. Shell and Exxonmobil was ready to withdraw investment in West-East gas pipeline which was the longest pipeline invested by CNPC. CNPC was isolated again because of its overlooking social responsibilities.

CNPC failed to realize that communities in which it operates is stake. CNPC should care about them and involve them into the management and understand what they care most. Then CNPC can understand their behaviors and tries to satisfy them as possible. CNPC has to modify its stakeholder view and make the communities and other stakeholders inclusive in the extended enterprise.

In the future, CNPC would face more and more stakeholders all over the world. Many latent and expected stakeholders will count, such as US government, European Union, Green Peace, all of which are powerful to influence operation of CNPC. Environment issues, human rights issues will be on the table of president of CNPC. CNPC has to consider all of them and analyze by stakeholder theories to find out attributes they have and sort them so that CNPC can satisfy and deal with them successfully. By doing so, CNPC would be developing with sustainability.

\section{Conclusion}

From analysis above, we can conclude that the stakeholder view of CNPC is dynamic over time. CNPC cares different stakeholders during different periods. At the very beginning, CNPC only cared one stakeholder-government because government stands all other stakeholders' interest. Government had all attributes of stakeholders. Once CNPC cared government and satisfied government, it satisfied all the stakeholders. Therefore, CNPC had to take so many social responsibilities. However, after China became a member of WTO, things were different. Government could not stand for all stakeholders any more. CNPC had to adjust its stakeholder view. However, CNPC stakeholders' view was over adjusted. During this period, CNPC focused too much on the economic value, overlooking the stakeholders who were really important to CNPC. This was why so many tragic accidents happened during this period.

Now, CNPC is experiencing a period of adjusting stakeholder views. Now CNPC is aggressively expanding all over the world. And this year, CNPC successfully acquired Calgary-based PetroKazakhstan Inc. This acquisition indicated that CNPC stakeholder view was becoming mature now. In this acquisition, CNPC really considered all stakeholders who might care about this deal, For example, Kazakhstan government, Kazakhstan National Oil Company and other bidders. CNPC satisfied Kazakhstan government by offering to sell 33\% shares to Kazakhstan national oil company and to set up a join venture with Shymkent Oil Refinery which is a subsidiary of Kazakhstan National Oil Company. This offer was quite important to succeed in this deal.

However, we can not neglect that CNPC is a state-owned company and government has majority stake in the company. This fact weakens the competitive advantage of CNPC. Some analysts claimed why CNOOC failed to acquire the Unocal is because Chinese government holds too many shares. This fact makes investors less confident in the CNOOC. This would be the case for CNPC. Government is also the most important stakeholders of CNPC. If CNPC will be continuing to expand all over the world, CNPC should consider it seriously. CNPC should learn something from the lesson of failure of acquiring Unocal. 
With the expansion of CNPC, it has to face some complexity. Human rights, culture factors and developed countries, undeveloped countries would be more important to shape the stakeholder view of CNPC. Actually, CNPC was already criticized for failing to protect the human rights in Sudan. Therefore, CNPC will be required to consider not only social responsibility in China but also in other countries where it is operating. Therefore, in the future, CNPC should manage latent and expected stakeholders and manage them ambiguity to mitigate risks.

\section{References}

Freeman, A stakeholder Approach in Strategy Management.

James E. Post, Lee E. Preston, \& Sybille Sachs (2002). The new stakeholder View in Managing the extended enterprise. Stanford University Press, 2002.

Ronald K.Mitchiell \& Donna J Wood. Defining the principle of who and what really counts in Toward a theory of stakeholder identification and salience.

Jeremy Hall \& Harrie Vredenburg, Stakeholder Ambiguity and Corporate Risk Strategies, University of Calgary.

CHINA: Oil sector reform yields mixed results, OX Research, Oxford, September 20, 2001, Pg1.

Fan, Hui, the gas well blowout is reminding companies of paying attention to social responsibilities, www.china5e.com, Sepember-06 2004.

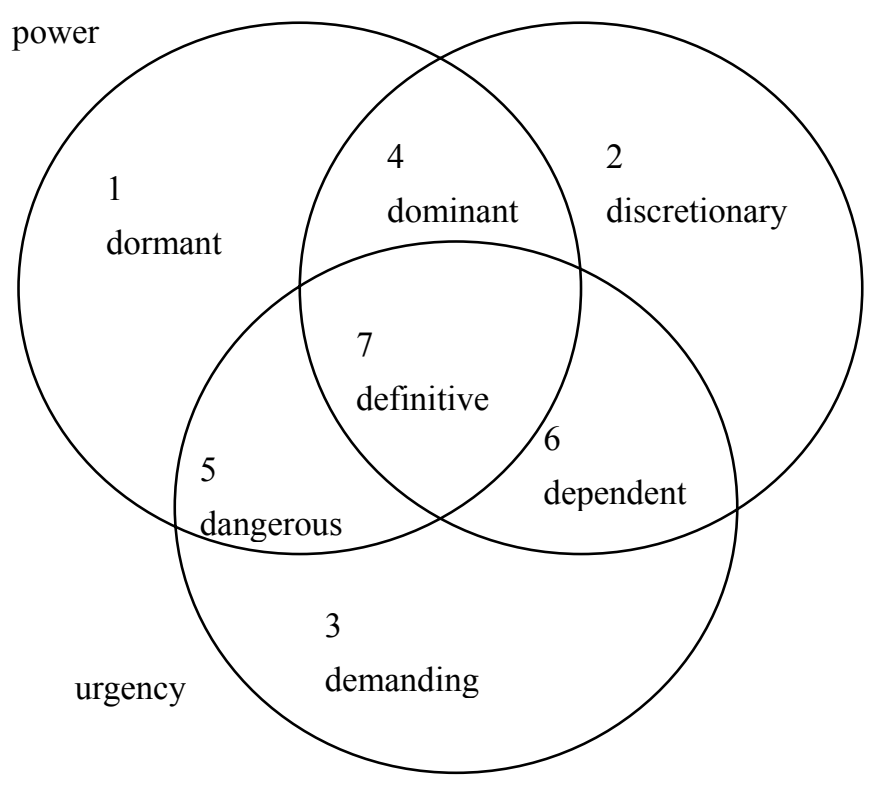

legitimacy

Figure 1. 